\title{
Olanzapine-samidorphan combination for schizophrenia or bipolar I disorder
}

\author{
Leslie L. Citrome, MD, MPH
}

A pproved by the FDA on May 28, 2021, olanzapine-samidorphan combination (OSC) (Lybalvi, manufactured and distributed by Alkermes, Inc. Waltham, MA USA) is intended to help mitigate some of the weight gain that can be anticipated with the use of olanzapine alone (Table, page 36). ${ }^{1-3}$ Olanzapine (Zyprexa, originally manufactured and distributed by Eli Lilly and Company/ Lilly USA, LLC, Indianapolis, IN USA) is a second-generation antipsychotic that has been available for a quarter century. ${ }^{4}$ Although highly efficacious, ${ }^{5,6}$ olanzapine has been associated with weight gain, at times substantial, as well as disturbances in glucose and lipid metabolism. ${ }^{7}$ The addition of samidorphan, an opioid antagonist, to olanzapine in a single tablet may act to decrease the amount of long-term weight gain that can be expected for some patients taking olanzapine alone, consequently minimizing the anticipated increase in waist circumference (a proxy for the measurement of burden imposed by metabolically active adipose tissue). Approval of OSC for the treatment of schizophrenia was based on 2 pivotal randomized controlled trials and their extension studies. ${ }^{8-11}$ Approval of OSC for bipolar I disorder (acute treatment of manic/mixed episodes as a monotherapy or adjunctive to lithium or valproate, and as a monotherapy maintenance treatment) was based on legacy studies conducted with olanzapine, after establishing that samidorphan does not alter the pharmacokinetics of olanzapine, including in combination with lithium or valproate. ${ }^{3,12,13}$ OSC should be distinguished from a different combination product, olanzapine-fluoxetine combination (Symbyax, originally manufactured and distributed by Eli Lilly and Company/ Lilly USA, LLC, Indianapolis, IN USA), approved for acute depressive episodes associated with bipolar I disorder and for treatment-resistant depression. ${ }^{14}$

OSC offers the potential to consider olanzapine earlier in the treatment of schizophrenia or bipolar I disorder, especially among practitioners who might otherwise be hesitant to prescribe this agent because of concerns over the risk of excessive weight gain.

OSC is available in 4 dosage strengths containing $5 \mathrm{mg}, 10 \mathrm{mg}, 15 \mathrm{mg}$, or $20 \mathrm{mg}$ of olanzapine; all tablets contain $10 \mathrm{mg}$ of samidorphan. ${ }^{2}$ The recommended starting dose for OSC mirrors the language contained

Dr. Citrome is Clinical Professor of Psychiatry and Behavioral Sciences, New York Medical College, Valhalla, New York. He is CURRENT PsYCHIATRY's Section Editor, Psychopharmacology.

\section{Disclosure}

No writing assistance or external financial support was utilized in the production of this article. Dr. Citrome has served as a consultant to AbbVie/Allergan, Acadia, Adamas, Alkermes, Angelini, Astellas, Avanir, Axsome, BioXcel, Boehringer Ingelheim, Cadent Therapeutics, Eisai, Enteris BioPharma, HLS Therapeutics, Impel, Intra-Cellular Therapies, Janssen, Karuna, Lundbeck, Lyndra, Medavante-ProPhase, Merck, Neurocrine, Novartis, Noven, Otsuka, Ovid, Relmada, Reviva, Sage, Sunovion, Teva, University of Arizona, and one-off ad hoc consulting for individuals/entities conducting marketing, commercial, or scientific scoping research; speaker for AbbVie/Allergan, Acadia, Alkermes, Angelini, Eisai, Intra-Cellular Therapies, Janssen, Lundbeck, Neurocrine, Noven, Otsuka, Sage, Sunovion, Takeda, Teva, and CME activities organized by medical education companies such as Medscape, NACCME, NEl, Vindico, and universities and professional organizations/ societies. He owns stocks (small number of shares of common stock): Bristol-Myers Squibb, Eli Lilly, J\&, Merck, Pfizer purchased $>10$ years ago; and has received royalties from Wiley (Editor-in-Chief, International Journal of Clinical Practice, through end 2019), UpToDate (reviewer), Springer Healthcare (book), and Elsevier (Topic Editor, Psychiatry, Clinical Therapeutics).

doi: $10.12788 /$ cp.0203
OSC is intended to mitigate some of the weight gain anticipated when using olanzapine alone 


\section{Clinical Point}

\section{Samidorphan does not alter the pharmacokinetics of olanzapine, including in combination with lithium or valproate}

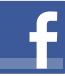

Discuss this article at www.facebook.com/ MDedgePsychiatry

\section{Table}

\section{Fast facts about olanzapine- samidorphan combination}

Brand name: Lybalvi

Class: Olanzapine-samidorphan combination consists of olanzapine, a second-generation antipsychotic, and samidorphan, an opioid antagonist

Indication: Schizophrenia in adults and bipolar I disorder in adults (acute treatment of manic or mixed episodes as monotherapy and as adjunct to lithium or valproate, and as maintenance monotherapy treatment)

Approval date: May 28, 2021

Availability date: October 2021

Manufacturer: Alkermes, Inc.

Dosing forms: Tablets (olanzapine/

samidorphan): $5 \mathrm{mg} / 10 \mathrm{mg}, 10 \mathrm{mg} / 10 \mathrm{mg}$, $15 \mathrm{mg} / 10 \mathrm{mg}$, and $20 \mathrm{mg} / 10 \mathrm{mg}$

Recommended dose: Schizophrenia: Initiate at $5 \mathrm{mg} / 10 \mathrm{mg}$ or $10 \mathrm{mg} / 10 \mathrm{mg}$ once daily; recommended dosage is $10 \mathrm{mg} / 10 \mathrm{mg}$, $15 \mathrm{mg} / 10 \mathrm{mg}$, or $20 \mathrm{mg} / 10 \mathrm{mg}$.

Bipolar I (manic or mixed): For monotherapy, initiate at $10 \mathrm{mg} / 10 \mathrm{mg}$ or $15 \mathrm{mg} / 10 \mathrm{mg}$ once daily; recommended dosage is $10 \mathrm{mg} / 10 \mathrm{mg}$, $15 \mathrm{mg} / 10 \mathrm{mg}$, or $20 \mathrm{mg} / 10 \mathrm{mg}$ once daily. For adjunctive to lithium or valproate, initiate at $10 \mathrm{mg} / 10 \mathrm{mg}$ once daily and recommended dosage is $10 \mathrm{mg} / 10 \mathrm{mg}, 15 \mathrm{mg} / 10 \mathrm{mg}$ or $20 \mathrm{mg} / 10 \mathrm{mg}$, once daily. For bipolar I maintenance monotherapy, administer at $5 \mathrm{mg} / 10 \mathrm{mg}, 10 \mathrm{mg} / 10 \mathrm{mg}, 15 \mathrm{mg} / 10 \mathrm{mg}$, or $20 \mathrm{mg} / 10 \mathrm{mg}$ once daily.

in the legacy olanzapine product label. ${ }^{4}$ For schizophrenia, the recommended initial dose (olanzapine/samidorphan) is $5 \mathrm{mg} / 10 \mathrm{mg}$ or $10 \mathrm{mg} / 10 \mathrm{mg}$ once daily. For bipolar I manic or mixed episodes, the recommended starting dose for monotherapy is $10 \mathrm{mg} / 10 \mathrm{mg}$ or $15 \mathrm{mg} / 10 \mathrm{mg}$, and for use with lithium or valproate, $10 \mathrm{mg} / 10 \mathrm{mg}$. For all indications, the recommended target dose can be $10 \mathrm{mg} / 10 \mathrm{mg}, 15 \mathrm{mg} /$ $10 \mathrm{mg}$, or $20 \mathrm{mg} / 10 \mathrm{mg}$, with $5 \mathrm{mg} / 10 \mathrm{mg}$ as an additional potential dose for maintenance monotherapy of bipolar I disorder. The maximum dose is $20 \mathrm{mg} / 10 \mathrm{mg}$ once daily. Because the amount of samidorphan in each tablet is fixed at $10 \mathrm{mg}$, combining tablets of OSC, or cutting OSC tablets in half, is not advisable.

\section{How it works}

Product labeling notes that olanzapine is an atypical antipsychotic, that its efficacy in schizophrenia or bipolar I disorder could be mediated through a combination of dopamine and serotonin type 2 (5HT2) antagonism, and that the mechanism of action of samidorphan could be mediated through opioid receptor antagonism. ${ }^{2}$

The pharmacodynamic profile of olanzapine is complex. ${ }^{2}$ It binds with high affinity to the following receptors: serotonin $5 \mathrm{HT} 2 \mathrm{~A} / 2 \mathrm{C}$, $5 \mathrm{HT} 6(\mathrm{Ki}=4,11$, and $5 \mathrm{nM}$, respectively), dopamine D1-4 $(\mathrm{Ki}=11-31 \mathrm{nM})$, histamine $\mathrm{H} 1(\mathrm{Ki}=7 \mathrm{nM})$, and adrenergic alpha-1 receptors $(\mathrm{Ki}=19 \mathrm{nM})$. Olanzapine is an antagonist with moderate affinity binding for serotonin 5HT3 $(\mathrm{Ki}=57 \mathrm{nM})$ and muscarinic M1-5 ( $\mathrm{Ki}=73,96,132,32$, and $48 \mathrm{nM}$, respectively). Olanzapine binds with low affinity to gamma aminobutyric acid type A (GABA-A), benzodiazepine, and beta-adrenergic receptors $(\mathrm{Ki}>10 \mu \mathrm{M})$. Olanzapine's muscarinic receptor affinity can explain why olanzapine can be associated with constipation, dry mouth, and tachycardia, all adverse reactions possibly related to cholinergic antagonism. Thus, OSC should be used with caution in patients with a current diagnosis or prior history of urinary retention, clinically significant prostatic hypertrophy, constipation, or a history of paralytic ileus or related conditions; a potential drug-drug interaction can be anticipated with concomitant use of anticholinergic medications. ${ }^{2}$ Other pharmacodynamic drug-drug interactions that can occur with the olanzapine component of OSC include the possibility that diazepam, alcohol, or other CNS-acting drugs may potentiate orthostatic hypotension, and there may be a need to reduce the dosage of concomitantly prescribed antihypertensive drugs in patients being treated for hypertension. Moreover, OSC is not recommended in patients receiving levodopa and dopamine agonists.

Samidorphan binds to the mu-, kappa-, and delta-opioid receptors $(\mathrm{Ki}=.052, .23$, and $2.7 \mathrm{nM}$, respectively). ${ }^{2}$ Samidorphan is an 
antagonist at the mu-opioid receptors with partial agonist activity at kappa- and deltaopioid receptors. A major human metabolite of samidorphan (N-dealkylated) binds to the mu-, kappa-, and delta-opioid receptors $(\mathrm{Ki}=.26,23$, and $56 \mathrm{nM}$, respectively), and functions as a mu-opioid receptor agonist. The N-oxide major human metabolite binds to mu-, kappa-, and delta-opioid receptors $(\mathrm{Ki}=8,110$, and $280 \mathrm{nM}$, respectively) and functions as a mu-opioid receptor antagonist. This profile differs from that of other opioid antagonists such as naltrexone. ${ }^{15,16}$

OSC is not a scheduled drug subject to the Controlled Substances Act. Because samidorphan functions as an opioid antagonist, OSC is contraindicated in patients using opioids or undergoing acute opioid withdrawal. ${ }^{2}$ To avoid precipitating opioid withdrawal, there should be at least a 7-day opioid-free interval from the last use of short-acting opioids, and at least a 14-day opioid-free interval from the last use of long-acting opioids, before initiating OSC. In emergency situations when an opioid is required, OSC should be discontinued. Patients who attempt to overcome opioid blockade while receiving OSC by using high or repeated doses of exogenous opioids could experience life-threatening or fatal opioid intoxication. Likewise, patients may have decreased tolerance to opioids if OSC therapy is interrupted or discontinued.

Regarding cardiac electrophysiology, OSC was not observed to prolong the electrocardiogram QTc interval to any clinically relevant extent when tested at doses up to $30 \mathrm{mg} / 30 \mathrm{mg}$ ( 1.5 times and 3 times the maximum recommended daily dosage of olanzapine and samidorphan, respectively). ${ }^{17}$

\section{Clinical pharmacokinetics}

The pharmacokinetics of both olanzapine and samidorphan are linear over the clinical dose range and there is no pharmacokinetic interaction between olanzapine and samidorphan after oral administration of OSC. ${ }^{2}$ Coadministration of OSC with lithium or valproate does not have a clinically significant effect on systemic exposure of lithium or valproate..$^{13}$ OSC steady-state concentrations of olanzapine and samidorphan are reached within 7 days, with accumulation at steady state being 2-fold for olanzapine and 1.3-fold for samidorphan (at 5 days). Elimination half-life for olanzapine is 35 to 52 hours, and for samidorphan, 7 to 11 hours. Olanzapine is metabolized primarily via UGT1A4 and CYP1A2, whereas samidorphan is primarily metabolized by CYP3A4. Consequently, concomitant use of OSC with strong CYP3A4 inducers is not recommended. The recommendation regarding CYP1A2 modulators and OSC are similar to those for olanzapine ${ }^{2,4}$ : consider reducing the dosage of the olanzapine component in OSC when used concomitantly with strong CYP1A2 inhibitors, and consider increasing the dosage of the olanzapine component in OSC when used concomitantly with CYP1A2 inducers. Because cigarette smoke contains polycyclic aromatic hydrocarbons that act as CYP1A2 inducers, ${ }^{18}$ olanzapine clearance is much higher in smokers than in nonsmokers. ${ }^{2}$ This translates to potentially clinically relevant differences when optimizing the dose. In a study of patients with schizophrenia, olanzapine concentrations were lower in self-reported smokers $(16.5,34.2$, and 60.9 $\mathrm{ng} / \mathrm{mL}$ ) than in self-reported nonsmokers (25.6, 43.4, and $113.2 \mathrm{ng} / \mathrm{mL})$ for dosages of 10,20 , and $40 \mathrm{mg} / \mathrm{d}$, respectively. ${ }^{19}$ In contrast, samidorphan pharmacokinetics are not affected by smoking status. ${ }^{2}$

No dose adjustment of OSC is needed in patients with hepatic or renal impairment; however, OSC is not recommended for patients with end-stage renal disease because this has not been specifically studied. ${ }^{2}$

\section{Efficacy}

The efficacy of OSC in the treatment of schizophrenia in adults is supported, in part, by the extensive legacy of studies of orally administered olanzapine. ${ }^{2}$ For OSC specifically, acute efficacy was primarily demonstrated in a randomized, double-blind, phase 3, 4-week study establishing superiority vs placebo in acutely exacerbated patients with schizophrenia. ${ }^{8}$ Mitigation of weight gain was assessed separately in a randomized,
Clinical Point

Olanzapine clearance is much higher in smokers, but samidorphan pharmacokinetics are not affected by smoking status 


\section{Clinical Point}

\section{Treatment with}

OSC was associated with statistically significantly less weight gain than treatment with olanzapine double-blind, phase 3, 24-week study comparing OSC with olanzapine in non-acute outpatients with schizophrenia. ${ }^{10}$ Both of these 2 trials were accompanied by 52 -week open-label extension studies. ${ }^{9,11}$

The 4-week study evaluated the antipsychotic efficacy of OSC in 401 patients experiencing an acute exacerbation or relapse of schizophrenia who required inpatient treatment. ${ }^{8}$ Patients were required to have a Positive and Negative Syndrome Scale (PANSS) total score $\geq 80$, with a score $\geq 4$ on at least 3 of selected positive symptoms, and a Clinical Global Impression-Severity (CGI-S) score $\geq 4$ at baseline and screening. Patients were required to be inpatients for the first 2 weeks of the study, and were encouraged to remain as inpatients for all 4 weeks. Patients were randomized to receive OSC, olanzapine, or placebo. Dosing was once-daily and flexible based on clinical response and tolerability for the first 2 weeks of the study, and fixed thereafter. Patients assigned to OSC could receive $10 \mathrm{mg} / 10 \mathrm{mg}$ or $20 \mathrm{mg} / 10$ $\mathrm{mg}$, and patients randomized to olanzapine could receive $10 \mathrm{mg}$ or $20 \mathrm{mg}$. The study compared OSC with placebo, with olanzapine serving as an active control. Treatment with OSC resulted in significant improvements in symptoms compared with placebo at Week 4 , as measured by changes in PANSS total scores from baseline. Improvement in PANSS scores with OSC relative to placebo was similar to that observed with olanzapine. The antipsychotic efficacy of OSC relative to placebo was also supported by improvements in CGI-S scores. Thus, the inclusion of samidorphan in OSC did not negatively impact the antipsychotic efficacy of olanzapine.

In the 24-week study, 561 patients were randomized to OSC or olanzapine. ${ }^{10}$ There was no placebo control. Patients were treated with doses of OSC $10 \mathrm{mg} / 10 \mathrm{mg}$ or $20 \mathrm{mg} /$ $10 \mathrm{mg}$, or with doses of olanzapine $10 \mathrm{mg}$ or $20 \mathrm{mg}$. Dosing was flexible for the first 4 weeks of the study and fixed thereafter. Eligible patients were age 18 to 55 years (younger than the 4-week study, where the maximum age was 70 years), with a body mass index of 18 to $30 \mathrm{~kg} / \mathrm{m}^{2}$ (lower than the upper limit of $40 \mathrm{~kg} / \mathrm{m}^{2}$ used in the 4 -week study). In contrast to the acutely exacerbated patients in the 4-week study, patients were required to have a PANSS total score of 50 to 90 , CGI-S score $\leq 4$, and symptoms suitable for outpatient treatment. The co-primary endpoints were percent change from baseline in body weight and proportion of patients who gained $\geq 10 \%$ body weight at Week 24 . Treatment with OSC or olanzapine resulted in similar improvements in PANSS total and CGI-S scores, but treatment with OSC was associated with statistically significantly less weight gain than treatment with olanzapine, and with a smaller proportion of patients who gained $\geq 10 \%$ body weight. The least squares mean percent weight change from baseline to the end of treatment was $4.2 \%$ with OSC vs $6.6 \%$ with olanzapine. Although patients treated with OSC or olanzapine had similar weight gain for the first 4 weeks of treatment, OSC weight gain stabilized after approximately the 6th week, whereas patients who received olanzapine continued to gain weight throughout the remainder of the treatment period. The risk of gaining $\geq 10 \%$ body weight from baseline was reduced by $50 \%$ with OSC compared with olanzapine. Moreover, the odds of gaining $\geq 7 \%$ body weight from baseline at Week 24 were also reduced by $50 \%$ for OSC compared with olanzapine. OSC was also associated with smaller increases in waist circumference compared with olanzapine, which was observable as early as Week 1 . The risk of experiencing a $5-\mathrm{cm}$ increase in waist circumference was $50 \%$ lower for patients treated with OSC vs olanzapine, a relevant threshold in assessing risk of all-cause mortality and cardiovascular disease..$^{20}$ However, changes in metabolic laboratory parameters in patients treated with OSC or olanzapine were generally small and were similar between groups. In addition, there were little differences between the 2 treatment groups in metabolic parameter changes considered to be of potential clinical significance, based on commonly used thresholds.

Patients on stable, chronic olanzapine therapy were not specifically studied, so the 
weight effect of switching from olanzapine to OSC is unknown.

For bipolar I manic or mixed episodes, the use of OSC as monotherapy or in combination with lithium or valproate, as well as for maintenance monotherapy, was approved based on legacy clinical trials with olanzapine, as described in product labeling, ${ }^{2,4}$ as well as pharmacokinetic data evidencing that OSC did not have a clinically significant effect on the pharmacokinetics of lithium or valproate. ${ }^{13} \mathrm{~A}$ study is in progress to evaluate the effect of OSC compared with olanzapine on body weight in young adults with schizophrenia, schizophreniform, or bipolar I disorder who are early in their illness (ClinicalTrials.gov identifier: NCT03187769).

\section{Overall tolerability and safety}

The systemic safety and tolerability profile for OSC would be expected to be similar to that for olanzapine, unless there are adverse events that are specifically related to the samidorphan component. In the 4-week acute study described above, ${ }^{8}$ adverse events that occurred at least twice the rate of placebo with OSC included increased weight $(18.7 \%$, $14.3 \%, 3.0 \%$, for OSC, olanzapine, and placebo, respectively), somnolence $(9.0 \%, 9.8 \%$, $2.2 \%)$, dry mouth $(7.5 \%, 5.3 \%, 0.7 \%)$, and headache $(6.0 \%, 5.3 \%, 3.0 \%)$. In the 24 -week study, ${ }^{10}$ which did not have a placebo control, the most commonly reported adverse events $(\geq 10 \%$ of patients) were increased weight ( $24.8 \%$ vs $36.2 \%$ for OSC vs olanzapine), somnolence $(21.2 \%$ vs $18.1 \%)$, dry mouth $(12.8 \%$ vs $8.0 \%)$, and increased appetite $(10.9 \%$ vs $12.3 \%)$. In both studies, rates of discontinuation due to adverse events were low and similar between groups (in the 4-week study, $1.5 \%$ for OSC, $2.3 \%$ for olanzapine, and $5.2 \%$ for placebo; in the 24 -week study, $12.0 \%$ for OSC and $9.8 \%$ for olanzapine).

In the 2 open-label, phase 3, 52-week extension studies, ${ }^{9,11}$ long-term tolerability was evidenced by low rates discontinuation due to adverse events $(\leq 6 \%)$. Neither extension study reported any clinically meaningful changes over time in hematology, biochemistry, vital signs, or electrocardiogram parameters. ${ }^{3}$ In addition to durability of antipsychotic response as evidenced by sustained improvements in PANSS and CGI-S scores over time, waist circumference and weight remained stable, and the observed long-term changes in weight were consistent with weight changes observed with other second-generation antipsychotics. ${ }^{3}$ Longterm changes in metabolic laboratory parameter values were small and remained stable, and there was little change in glycosylated hemoglobin (hemoglobin A1c) values, which suggests that glycemic control was maintained with long-term OSC treatment. ${ }^{3}$ Caveats to consider are that the extension studies were open label without comparators, and they may have selected for patients who responded favorably to OSC treatment in the preceding studies. ${ }^{3}$

Warnings and precautions in OSC product labeling are generally similar to those for other second-generation antipsychotics ${ }^{21}$ other than warnings and precautions specifically related to samidorphan being an opioid antagonist, and special mention of "Drug Reaction with Eosinophilia and Systemic Symptoms" and "Anticholinergic (Antimuscarinic) Effects" warnings, which also are contained in the olanzapine legacy label. ${ }^{2,4}$

\section{Summary}

Olanzapine has a plethora of evidence supporting its robust efficacy profile ${ }^{5,6}$; however, its use is stymied by an unfavorable weight and metabolic profile. ${ }^{7}$ OSC may help mitigate at least some of the weight gain that would be expected with the use of olanzapine alone in the long-term treatment of patients with schizophrenia or bipolar I disorder. The addition of samidorphan does not deleteriously affect the efficacy of olanzapine, but decreases the risk of gaining $\geq 10 \%$ or $\geq 7 \%$ of baseline body weight by approximately $50 \%$ compared with olanzapine alone. Increase in waist circumference, a proxy for how much metabolically active fat one has, is lower with OSC than it is with olanzapine. Because samidorphan is an opioid receptor antagonist, OSC is contraindicated in patients using

\section{Clinical Point}

Longer-term use of
OSC is supported by
extension studies
lasting one year
extension studies lasting one year 


\section{Clinical Point}

Do not prescribe OSC for patients using opioids or those undergoing acute opioid withdrawal

\section{Related Resource}

- Olanzapine and samidorphan (Lybalvi) prescribing information. https://www.lybalvi.com/lybalvi-prescribing-information.pdf

Drug Brand Names

Diazepam • Valium Lithium • Eskalith, Lithobid Olanzapine - Zyprexa

Olanzapine-fluoxetine combination - Symbyax

opioids and in those undergoing acute opioid withdrawal. Dosage strengths available for OSC parallel those for olanzapine, and all strengths including the same fixed dose of samidorphan-10 $\mathrm{mg}$ - so advise patients not to double up on the tablets, and to not split them.

\section{References}

1. US Food and Drug Administration. NDA 213378 approval letter. May 28, 2021. Accessed November 24, 2021. https:// www.accessdata.fda.gov/drugsatfda_docs/nda/2021/213 3780rig1Orig2s000Approv.pdf

2. Alkermes, Inc. LYBALVITM (olanzapine and samidorphan) tablets, for oral use. Prescribing information. May 2021. Accessed November 24, 2021. https://www.lybalvi.com/ lybalvi-prescribing-information.pdf

3. Citrome L, Graham C, Simmons A, et al. An evidencebased review of OLZ/SAM for treatment of adults with schizophrenia or bipolar I disorder. Neuropsychiatr Dis Treat. 2021;17:2885-2904.

4. Eli Lilly and Company. ZYPREXA (olanzapine) tablet for oral use; ZYPREXA ZYDIS (olanzapine) tablet, orally disintegrating for oral use; ZYPREXA intramuscular (olanzapine) injection, powder, for solution for intramuscular use. Prescribing information. February 2021. Accessed November 24, 2021. https://pi.lilly.com/us/ zyprexa-pi.pdf

5. Citrome L, McEvoy JP, Todtenkopf MS, et al. A commentary on the efficacy of olanzapine for the treatment of schizophrenia: the past, present, and future. Neuropsychiatr Dis Treat. 2019;15:2559-2569.

6. Meftah AM, Deckler E, Citrome L, et al. New discoveries for an old drug: a review of recent olanzapine research. Postgrad Med. 2020;132(1):80-90.

7. Citrome L, Holt RI, Walker DJ, et al. Weight gain and changes in metabolic variables following olanzapine treatment in schizophrenia and bipolar disorder. Clin Drug Investig. 2011;31(7):455-482.
8. Potkin SG, Kunovac J, Silverman BL, et al. Efficacy and safety of a combination of olanzapine and samidorphan in adult patients with an acute exacerbation of schizophrenia: outcomes from the randomized, phase 3 ENLIGHTEN-1 study. J Clin Psychiatry. 2020;81(2):19m12769.

9. Yagoda S, Graham C, Simmons A, et al. Long-term safety and durability of effect with a combination of olanzapine and samidorphan in patients with schizophrenia: results from a 1-year open-label extension study. CNS Spectr. 2021;26(4):383-392.

10. Correll CU, Newcomer JW, Silverman B, et al. Effects of olanzapine combined with samidorphan on weight gain in schizophrenia: a 24-week phase 3 study. Am J Psychiatry. 2020;177(12):1168-1178.

11. Kahn RS, Silverman BL, DiPetrillo L, et al. A phase 3 , multicenter study to assess the 1-year safety and tolerability of a combination of olanzapine and samidorphan in patients with schizophrenia: results from the ENLIGHTEN-2 longterm extension. Schizophr Res. 2021;232:45-53.

12. US Food and Drug Administration. Drug approval package: Lybalvi. June 26, 2021. Accessed November 24, 2021. https://www.accessdata.fda.gov/drugsatfda_docs/nda/2 021/213378Orig1Orig2s000TOC.cfm

13. Sun L, Yagoda S, Yao B, et al. Combination of olanzapine and samidorphan has no clinically significant effect on the pharmacokinetics of lithium or valproate. Clin Drug Investig. 2020;40(1):55-64.

14. Eli Lilly and Company. SYMBYAX (olanzapine and fluoxetine) capsules for oral use. Prescribing information. September 2021. Accessed November 24, 2021. https:// pi.lilly.com/us/symbyax-pi.pdf

15. Wentland MP, Lu Q, Lou R, et al. Synthesis and opioid receptor binding properties of a highly potent 4-hydroxy analogue of naltrexone. Bioorg Med Chem Lett. 2005;15(8):2107-2110

16. Lee MW, Fujioka K. Naltrexone for the treatment of obesity: review and update. Expert Opin Pharmacother. 2009;10(11):1841-1845.

17. Sun L, Yagoda S, Xue H, et al. Combination of olanzapine and samidorphan has no clinically relevant effects on ECG parameters, including the QTc interval: results from a phase 1 QT/QTc study. Prog Neuropsychopharmacol Biol Psychiatry. 2020;100:109881.

18. Zhou SF, Yang LP, Zhou ZW, et al. Insights into the substrate specificity, inhibitors, regulation, and polymorphisms and the clinical impact of human cytochrome P450 1A2. AAPS J. 2009;11(3):481-494.

19. Citrome L, Stauffer VL, Chen L, et al. Olanzapine plasma concentrations after treatment with 10,20 , and $40 \mathrm{mg} / \mathrm{d}$ in patients with schizophrenia: an analysis of correlations with efficacy, weight gain, and prolactin concentration. J Clin Psychopharmacol. 2009;29(3):278-283.

20. Cerhan JR, Moore SC, Jacobs EJ, et al. A pooled analysis of waist circumference and mortality in 650,000 adults. Mayo Clin Proc. 2014;89(3):335-345.

21. Citrome L, Nasrallah HA. On-label on the table: what the package insert informs us about the tolerability profile of oral atypical antipsychotics, and what it does not. Expert Opin Pharmacother. 2012;13(11):1599-1613.

\section{Bottom Line}

Olanzapine-samidorphan combination (OSC) is intended to mitigate some of the weight gain anticipated when using olanzapine alone. For clinicians who have prescribed olanzapine and have seen its therapeutic benefits, OSC will be a welcome addition to the therapeutic armamentarium. For practitioners who may have avoided olanzapine entirely, OSC can provide another means of offering this therapeutic option and counter "olanzapine hesitancy." 